EXTENDED REPORT

\title{
Increased transendothelial migration of scleroderma lymphocytes
}

\author{
G H Stummvoll, M Aringer, J Grisar, C W Steiner, J S Smolen, R Knobler, W B Graninger
}

Ann Rheum Dis 2004;63:569-574. doi: 10.1136/ard.2002.004838

See end of article for authors' affiliations

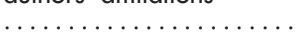

Correspondence to: Professor W Graninger, Department of Rheumatology, Vienna General Hospital, Waehringer Guertel 1820, A-1090 Vienna, Austria;

Winfried.Graninger@ akh-wien.ac.at

Accepted 4 June 2003
Background: CD4+ T lymphocytes play an important part in the pathogenesis of scleroderma (systemic sclerosis, SSc) and predominate in perivascular SSc skin lesions. Both soluble and membrane bound adhesion molecules are overexpressed in SSc, possibly influencing lymphocyte/endothelial cell (EC) contact.

Objective: To assess the transendothelial migration capacity of peripheral lymphocytes in vitro.

Patients and methods: Collagen was covered with human umbilical vein endothelial cells (HUVEC), and peripheral blood mononuclear cells (PBMC) of patients and matched healthy controls $(\mathrm{HC})$ were added in parallel experiments. Before and after fractionated harvest of non-adherent, bound, and migrated lymphocytes, the CD4/CD8 ratio and the lymphocytic expression of activation markers and adhesion molecules were analysed by fluorocytometry.

Results: 13 (SD 12)\% of the SSc PBMC migrated compared with only $5(5) \% \mathrm{HC} \mathrm{PBMC} \mathrm{(p<0.0002);} \mathrm{this}$ increase was primarily due to the migration of CD3+ T lymphocytes and mainly to a larger proportion of CD4+ cells within this CD3+ fraction (71 (SD 14)\% for SSc v 56 (14)\% for HC, p <0.03), leading to an increased CD4/CD8 ratio among migrated SSc lymphocytes in comparison with controls (3.3 (1.5) v 1.62 (0.93), $p<0.006$ ). Among migrated SSc CD4+ T lymphocytes, the frequency of HLA-DR+ cells was increased; migrated lymphocytes highly expressed the adhesion molecules CD1 1a, CD49d, CD29, and CD44.

Conclusion: Transendothelial migration of CD4+ T lymphocytes is enhanced in SSc, and migrating cells exhibit an activated phenotype. The data suggest that activated CD3+CD4+ lymphocytes as found in SSc peripheral blood are prone to transvascular migration, thus contributing to the formation of typical perivascular lymphocytic infiltrates.
S ystemic sclerosis (SSc) is a systemic inflammatory disease characterised by activation of circulating $\mathrm{T}$ lymphocytes, by increased levels of circulating mediators of inflammation, by the production of autoantibodies, and by typical local inflammatory infiltrates. ${ }^{1-5}$

The excessive accumulation of collagen in the skin and in the inner organs of patients with SSc has been suggested to be a consequence of immune processes clustered within and around small vessels. ${ }^{6}$ In its early stages, SSc is characterised by both endothelial damage $\mathrm{e}^{7}$ and perivascular infiltrations with an accumulation of lymphocytes. ${ }^{6-10}$ In the skin, these lymphocytes predominantly consist of CD4+ $\mathrm{T}$ cells that express increased amounts of activation markers and adhesion molecules on their surfaces. ${ }^{6}{ }^{11}{ }^{12}$ Interestingly, endothelial cells (EC) in the skin exhibit corresponding surface alterations, suggestive of an activated and pro-adhesive phenotype. ${ }^{12-15}$

In the peripheral blood of patients with SSc, T cells express markers of activation ${ }^{16}$ and are oligoclonally expanded..$^{17}$ Though the total number of $\mathrm{CD} 3+\mathrm{T}$ cells is decreased, the CD4/CD8 ratio in peripheral blood is increased. ${ }^{16}{ }^{19-21}$ However, it is not clear whether these activated $\mathrm{T}$ cells are already systemically predetermined for migration or whether transendothelial migration is mediated by direct contact of SSC PBMC and SSc EC and local events only. To answer this question, we investigated the lymphocytic migration through monolayers of human umbilical vein endothelial cells (HUVEC) in patients with SSc and in HC, because HUVEC express the same adhesion molecules relevant for lymphocytic migration ${ }^{22} 23$ as human arterial and human venous EC and show phenotypical homogeneity and stability during cultivation. ${ }^{24}{ }^{25}$ In addition, we evaluated the migrated CD4+ and CD8+ T cell subsets for possible differences in their expression of activation markers and adhesion molecules.

On the basis of the histopathological changes typical for SSc, we suggested that CD4+ lymphocytes would predominate among migrating $\mathrm{T}$ cells if the propensity to migrate was already a feature of circulating SSc lymphocytes.

\section{PATIENTS AND METHODS}

Patients

Heparinised peripheral blood was obtained from 12 white patients (10 female, 2 male, mean age 54.9 (SD 15.0) years) fulfilling the American College of Rheumatology criteria for $\mathrm{SSc}^{26}$; six patients had diffuse SSc, six had the limited type of the disease. Among our patients, 11 of 12 had active skin disease: two patients were in the very early oedematous phase of skin involvement; eight had evidence for active cutaneous disease as indicated by a total skin score $>20^{27}$ or a deterioration of the total skin score since the last observation 28; and one patient had stable cutaneous SSc but without showing signs of atrophy which are indicative for the late phase of cutaneous SSc. ${ }^{29}$ Eight of our patients with SSc had a duration of skin involvement $<5$ years (2.5 (SD 1.0) years), four patients had longer lasting cutaneous SSc (23.3 (10.1) years). These last four patients had evidence for still active cutaneous SSc.

Abbreviations: $B N D$, bound; $E C$, endothelial cells; $H C$, healthy controls; HUVEC, human umbilical vein endothelial cells; MIG, migrated; NAD, non-adherent; PBS, phosphate buffered saline; SSc, systemic sclerosis; TEM, transendothelial migration 
Table 1 Patients with SSc, clinical manifestations and treatment

\begin{tabular}{ll}
\hline Number of patients & 12 \\
Male/female & $2 / 10$ \\
Age (years), mean (SD) & $54.9(15.0)$ \\
Disease duration (years), mean (SD) & $12.4(3.5)$ \\
Diffuse SSc & $6(50)$ \\
Limited SSc & $6(50)$ \\
Organ involvement & \\
Pulmonary fibrosis & $8(67)$ \\
Pulmonary hypertension & $3(25)$ \\
$\quad$ Oesophageal & $9(75)$ \\
$\quad$ Renal & $2(17)$ \\
$\quad$ Cardiac & $1(8)$ \\
Serological findings & \\
ANA positive & $12(100)$ \\
Anti-Scl-70 positive & $5(42)$ \\
Anticentromere positive & $1(8)$ \\
CRP $>10$ mg/l & $1(8)$ \\
& \\
Treatment & \\
Cyclosporin A & $1(8)$ \\
Prednisolone $\leqslant 10$ mg & $3(25)$ \\
Extracorporeal photopheresis* & $5(42)$ \\
\hline Results are shown as No (\%) unless otherwise indicated. \\
*Blood was drawn before the respective photopheresis cycle after a \\
treatment-free interval of 3 months.
\end{tabular}

Data on clinical manifestations (skin, pulmonary, cardiac, renal, oesophageal, gastrointestinal), serological findings (autoantibodies, C reactive protein), and treatment were recorded (table 1). Eleven healthy subjects ( 10 female, 1 male, mean age 55.6 (SD 15.25) years) served as a control group. In each experiment, patients and controls were tested in parallel. All patients and controls gave informed consent to venepuncture and analysis of $20 \mathrm{ml}$ of heparinised venous blood.

\section{Preparation and culture of PBMC and EC}

PBMC were freshly isolated over a Ficoll-Hypaque gradient, washed, and counted on a haemocytometer.

Because HUVEC resemble human arterial and human venous EC in their expression of adhesion molecules and because, in striking contrast, human EC lines do not, HUVEC were regarded a good model for observing EC/lymphocyte interactions..$^{22}{ }^{30} 31$ We used EC harvested from human umbilical cord veins by collagenase digestion, as described. ${ }^{32}$ The culture medium of EC consisted of MCDB-M 104 (Gibco, Paisley, UK) supplemented with $20 \%$ fetal calf serum, $24 \mu \mathrm{g} /$ $\mathrm{ml}$ endothelial cell growth supplement (TC Laevosan, Linz, Austria), $50 \mathrm{U} / \mathrm{ml}$ heparin, $2 \mathrm{mM}$ L-glutamine (Gibco), $100 \mathrm{U} / \mathrm{ml}$ penicillin (Gibco), and $100 \mathrm{mg} / \mathrm{ml}$ streptomycin (Gibco). EC were removed from the culture flasks with trypsin-EDTA (Gibco). Because HUVEC retain phenotypical homogeneity and stability upon cultivation and in order to allow comparisons with previous studies ${ }^{22}{ }^{24}$ EC of the third to fourth passage were used for the assay of transendothelial migration (TEM).

\section{Assay of TEM}

Monolayers of EC on collagen gels

To study TEM, an in vitro assay was used as previously described $^{33}$ (fig 1). Collagen gels were formed in $16 \mathrm{~mm}$ macrowell tissue culture plates of $50 \%$ bovine collagen (Collagen Biomaterials, Palo Alto, CA, USA), 7\% $0.1 \mathrm{M}$ $\mathrm{NaOH}, 10 \%$ highly concentrated phosphate buffered saline (PBS; $10 \times$ PBS by Gibco), and $33 \%$ distilled water. EC $\left(5 \times 10^{5}\right.$ per well) were incubated overnight to form a confluent monolayer on the collagen gels. Confluence was carefully controlled by two different investigators for each single well

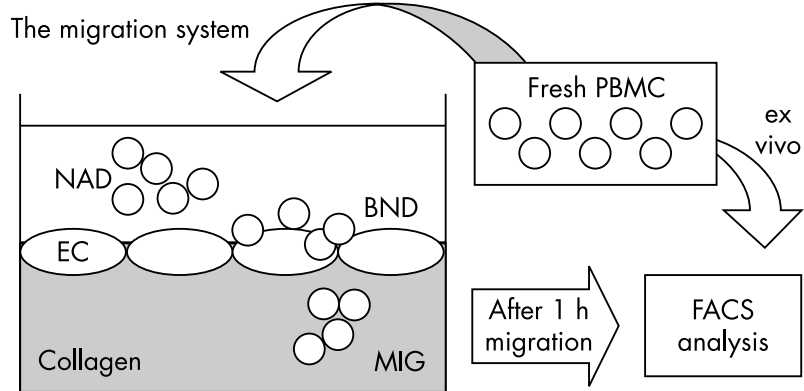

Figure 1 Assay of transendothelial migration. HUVEC after the third to fourth passage formed confluent monolayers on collagen gels after overnight incubation. On the second day of the experiment, we added fresh PBMC, obtained from SSc and matched $\mathrm{HC}$ and processed them in parallel experiments. After 1 hour of migration we analysed the harvested cell fractions (NAD, BND, MIG) and ex vivo stained PBMC by fluorocytometry. NAD, non-adherent; BND, bound; MIG, migrated, EC, endothelial cells, PBMC peripheral blood mononuclear cells.

by phase contrast microscopy; wells with a disrupted EC monolayer were excluded.

\section{Lymphocyte migration}

PBMC $\left(3 \times 10^{6}\right)$ resuspended in fresh EC culture medium were added onto the EC monolayers and incubated at $37^{\circ} \mathrm{C}$. Because antibody dependent cellular cytotoxicity ${ }^{74}$ could lead to defects in the HUVEC monolayer after longer periods of incubation, we kept the system free of SSc serum and the migration time to 1 hour, which had previously been determined to give optimal results. ${ }^{34 a}$

\section{Collection of lymphocyte fractions}

After migration, PBMC were recovered in three fractions: (a) cells that were non-adherent (NAD) to the endothelial cells were removed by gently washing three times with culture medium; $(b)$ cells that bound (BND) to the EC monolayer were then recovered by rinsing each well twice with warm $\left(37^{\circ} \mathrm{C}\right)$ Puck's EDTA, twice with warm $\left(37^{\circ} \mathrm{C}\right)$ EGTA $\left(0.5 \times 10^{-3} \mathrm{M}\right.$ EGTA in PBS $)$, and once with cold $\left(5^{\circ} \mathrm{C}\right)$ Puck's EDTA; $(c)$ finally, cells that had migrated (MIG) into the collagen gels were recovered. The collagen gels were gently stirred with a pipette tip, $0.7 \mathrm{ml}$ collagenase solution ( $0.1 \%$ collagenase (Sigma, St Louis, MI, USA), $1 \%$ fetal calf serum, 50 mM Hepes buffer (Sigma) in Hanks's balanced salt solution) was added, and the culture plate was incubated at $37^{\circ} \mathrm{C}$ for 40 minutes. Subsequently, the migrating population was recovered by washing the wells twice with PBS.

The PBMC recovered in each population (that is, NAD, BND, MIG) were centrifuged, resuspended in culture medium, and counted with a haemocytometer. In SSc, we recovered $11.71(7.24) \times 10^{6}$ cells in NAD (mean (SD)), 2.84 (5.00) in BND, and 2.46 (3.39) in MIG, respectively; in $\mathrm{HC}$, we recovered 11.71 (7.24) in NAD, 1.53 (2.10) in BND, and 0.88 (1.12) in MIG, respectively. The intra-assay variability was $8(1) \%$. Additional analyses by fluorocytometry were performed as described below.

\section{Preparation and labelling of peripheral blood cells}

Freshly prepared PBMC and the three fractions obtained after the incubation (NAD, BND, MIG) were stained in parallel according to standard procedures using antibodies against CD3, CD4, CD8, CD1la, CD25, CD69, HLA-DR (Becton Dickinson, San Jose, CA, USA), CD29, CD49d (Immunotech, Marseille, France), CD44 (Pharmingen, San Diego, CA, USA), CD45RO, CD54 (Serotec, Raleigh, NC, USA) directly conjugated to fluorescein isothiocyanate (FITC), phycoerythrin (PE), or peridinin chlorophyll protein 


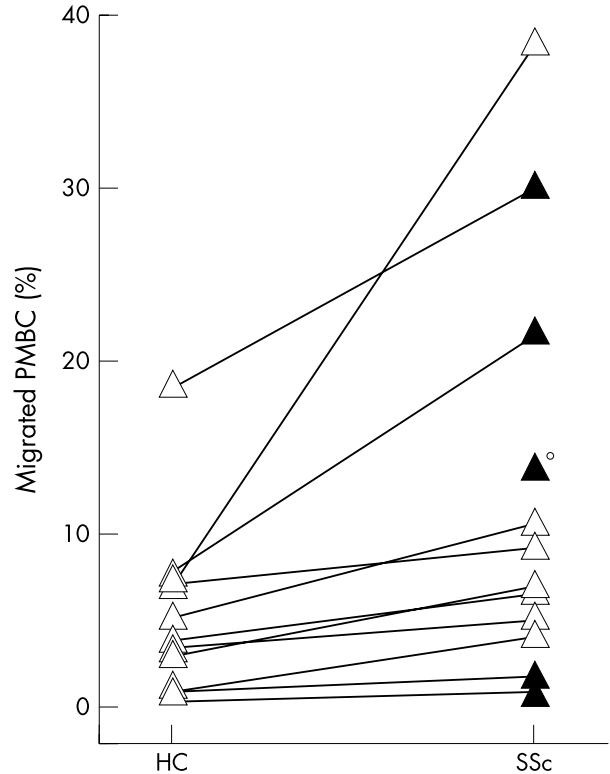

Figure 2 Increased transendothelial migration of SSc PBMC. Testing $\mathrm{PBMC}$ of $\mathrm{SSC}$ and $\mathrm{HC}$ in parallel experiments. Filled triangles indicate diffuse SSc, open triangles indicate limited disease, and the small circle indicates that the respective negative control had highly activated lymphocytes and developed influenza the next day. This single sample was therefore excluded from all analyses.

(PerCP). Isotype matched antibodies to irrelevant antigens conjugated to FITC (Dako, Glostrup, Denmark), PE, or PerCP (both from Becton Dickinson) served as negative controls.

\section{Fluorocytometry}

Immediately after staining, cells were analysed on a BectonDickinson FACScan fluorocytometer. Gates were carefully set for lymphocytes, excluding the monocyte population. ${ }^{35}$ Cells brighter than the respective isotype control were defined as positive in surface immunofluorescence.

\section{Detection of autoantibodies}

In our patients with SSc, antinuclear antibodies and anti-Scl70 antibodies were detected by indirect immunofluorescence and Ouchterlony double immunodiffusion, respectively, according to standard procedures. All patient sera were additionally analysed for anticentromere antibodies by line immunoassay, which has been considered a reliable alternative to conventional techniques with an, at least, similar sensitivity and specificity. ${ }^{36}$

\section{Statistics}

Numeric data are expressed as mean (SD). Student's $t$ tests and paired $t$ tests were employed for the comparison of groups and paired samples, respectively. Fisher's exact test and $\chi^{2}$ test were used to compare non-parametric variables in $2 \times 2$ and $2 \times 4$ tables, respectively. Pearson correlation coefficients were calculated for investigating possible associations between variables. The predefined primary variables were the percentage of migrated PBMC and the CD4/CD8 ratio, for which $p$ values $<0.025$ (two comparisons) were considered significant. For all other variables, the $\mathrm{p}$ values are regarded as descriptive and are thus not corrected for.

\section{RESULTS}

Increased migration of PBMC and T lymphocytes in SSc compared with controls

Testing PBMC of SSc and HC in parallel experiments, we found that $13(12) \%$ of the SSc PBMC migrated compared with only $5(5) \%$ HC PBMC, with the percentage MIG of patients with SSc always higher than that of the healthy subjects tested on the same day $\left(\mathrm{p}<0.0002, \chi^{2}\right.$ test; fig 2$)$. Moreover, the proportion of SSc T lymphocytes among the migrated cells was higher than that of HC T lymphocytes (67 $(14) \% \quad v 58(13) \%)$. There was a significant correlation between $\mathrm{CD} 3+$ cell migration and total PBMC migration $\left(r^{2}=0.55, \mathrm{p}=0.006\right)$. Therefore, the increased migration of SSc PBMC is, at least in part, due to an increased propensity of $\mathrm{CD} 3+\mathrm{T}$ lymphocytes towards transendothelial migration.

Increased migration of CD3+CD4+ lymphocytes in SSc Fluorocytometry further showed that the increased migration of T lymphocytes of patients with SSc was mainly due to an increase in CD4+ cells within the migrated CD3+ fraction (71 (14)\% in SSc $v 56(14) \%$ in $\mathrm{HC}, \mathrm{p}<0.03)$. Interestingly, the proportions of $\mathrm{CD} 3+\mathrm{CD} 4+$ cells of $\mathrm{HC}$, but not of SSc, were lower in the MIG (56 (14)\%) fraction than in PBMC before migration (68 (11)\%, p<0.05; table 2).

Vice versa, and in accordance with the literature on cell migration, the frequency of $\mathrm{CD} 3+\mathrm{CD} 8+$ lymphocytes was increased in the MIG fraction of HC cells, ${ }^{33}$ but not in the MIG fraction of SSc lymphocytes (43 (14) v 29 (15), respectively, $\mathrm{p}<0.04$; table 2 ), indicating that SSc CD8+ lymphocytes undergo TEM, but to a lesser degree than SSc CD4+ or HC CD8+ T cells.

\section{Rise in the CD4/CD8 ratio in migrated SSc lymphocytes}

In SSc, reports on changes in the distribution of $\mathrm{T}$ cell subsets suggested a decreased number of $\mathrm{CD} 3+\mathrm{T}$ cells and an increased CD4/CD8 ratio in peripheral blood which is, at least in part, due to a greater resistance of CD4+ lymphocytes to apoptotic stimuli. ${ }^{16-21}$ In the present study, we observed only a slightly increased CD4/CD8 ratio when staining lymphocytes immediately after isolation (ex vivo fraction, 3.18 (1.99) for SSc $v 2.56$ (1.13) for HC, p=NS). After TEM, the CD4/CD8 ratio increased in $8 / 12$ patients with SSc (to $3.27(1.54)$ ) but decreased in $10 / 11 \mathrm{HC}$ (to 1.62 (0.93), $\mathrm{p}<0.002$ calculated by Fisher's exact test; $\mathrm{p}<0.006$ in unpaired $t$ test; table 2, fig 3).

Table 2 Distribution of $C D 3+C D 4+$ cells, CD3+CD8+ cells, and the CD4/CD8 ratio

\begin{tabular}{|c|c|c|c|c|c|c|}
\hline & \multicolumn{2}{|c|}{$\%$ CD3+CD4+ } & \multicolumn{2}{|c|}{$\%$ CD3+CD8+ } & \multicolumn{2}{|l|}{ CD4/CD8 } \\
\hline & $\mathrm{HC}$ & SSc & $\mathrm{HC}$ & SSc & $\overline{\mathrm{HC}}$ & SSc \\
\hline Ex vivo & $68(11)$ & $69(16)$ & $28(9)$ & $30(15)$ & $2.56(1.13)$ & 3.18 (1.99) \\
\hline NAD & 71 (8) & 69 (15) & $28(9)$ & $28(18)$ & $2.76(0.89)$ & $3.26(1.91)$ \\
\hline BND & 58 (15) & $62(16)$ & 42 (18) & 38 (17) & $1.66(1.04)$ & $2.68(1.78)$ \\
\hline MIG & $56(14)^{*}$ & $71(15)^{*}$ & $43(14)^{*}$ & $29(15)^{*}$ & $1.62(0.93)^{*}$ & $3.27(1.54)^{*}$ \\
\hline
\end{tabular}

Results are shown as mean(SD).

$N A D$, non-adherent; $B N D$, bound; $M I G=$ migrated.

*Denotes $\mathrm{p}<0.05$ (unpaired $t$ test) between SSc and $\mathrm{HC}$ lymphocyte fractions. 


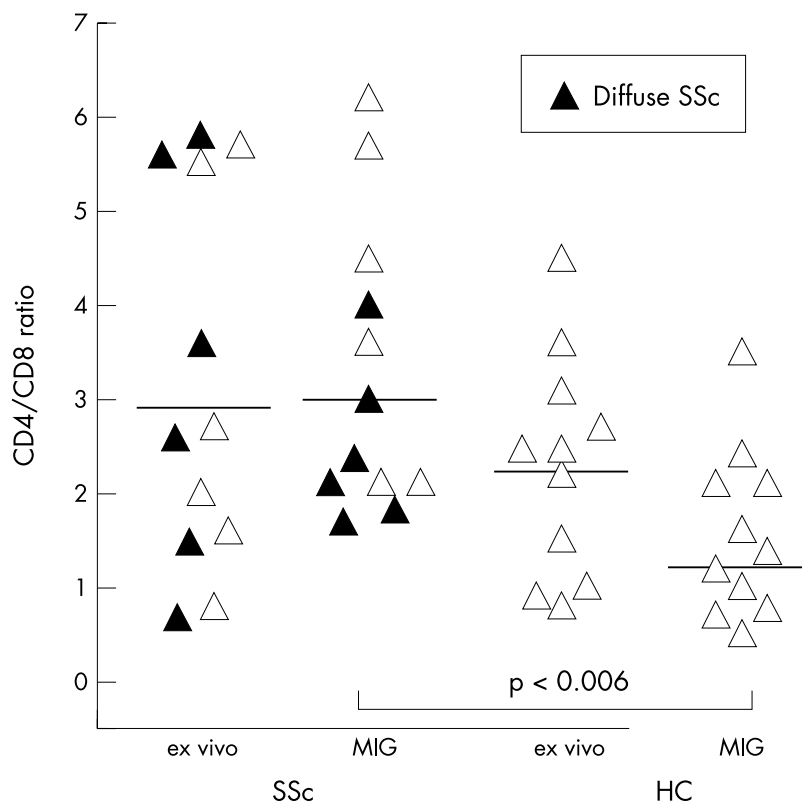

Figure 3 Rise in the CD4/CD8 ratio in migrated SSc lymphocytes. The $\mathrm{CD} 4 / \mathrm{CD} 8$ ratio in patients with SSc was only slightly raised ex vivo $(p=N S)$, but increased in $8 / 12$ patients with SSc and decreased in 10/ $11 \mathrm{HC}$, leading to a significantly raised CD4/CD8 ratio in migrated lymphocytes of patients with SSc when compared with $\mathrm{HC}$ (for details see table 2).

\section{Increased HLA-DR positive cells among migrated SSc CD4+ lymphocytes}

Among freshly isolated lymphocytes and the NAD fraction, we found low frequencies of HLA-DR positive CD4+ lymphocytes in both HC $(5(3) \%$ and $4(2) \%$, respectively) and SSc (7 (6)\% and $6(5) \%$, respectively; table 3$)$.

In $\mathrm{HC}$ the frequencies of CD4+DR+ lymphocytes were higher in the BND fraction (10 (7)\%), and in the MIG fraction $(14(10) \%)$. In SSc, we found an even more pronounced increase of CD4+DR+ lymphocytes in the BND fraction $(14(12) \%)$ and a further increase in the MIG fraction ( 31 (23)\%, p < 0.04 when compared with HC).

The frequencies of CD4+CD25+ were similar for SSc and HC: $19(13) \%$ and $13(6) \%$, respectively $(p=N S)$ in the PBMC analysed ex vivo before TEM and 31 (38)\% and 36 (37)\%, respectively $(p=N S)$ in the MIG population. In addition, also CD4+CD69+ cell frequencies tended to be higher among migrated lymphocytes than ex vivo in SSC (table 3).

\section{CD45Ro is highly expressed among migrated CD4+}

In HC and SSc, the proportions of CD45Ro+ cells among the CD4+ population in the MIG fraction amounted to $74(9) \%$ in HC and $77(10) \%$ in SSc. This was higher than in the NAD
(57 (12)\% and 59 (16)\%, respectively, $p<0.02$ for both) and slightly higher than in the BND fraction $(65(16) \%$ and 70 (15)\%, respectively, $\mathrm{p}=\mathrm{NS}$ for both).

\section{CD54 (ICAM-1) is increased on migrated CD4+ lymphocytes}

Similar frequencies of CD4+CD54+ lymphocytes were present ex vivo and in the NAD fraction of both HC (7 (6)\% and 6 (5)\%, respectively) and SSc $(6(7) \%$ and $4(4) \%$, respectively). However, the proportion of CD4+CD54+ cells increased in the BND fractions of HC and SSc ( $15(11) \% v 16(12) \%, \mathrm{p}<0.02$ and $\mathrm{p}<0.04$, respectively) and in the MIG fraction, with a more pronounced increase among SSc cells $(26(20) \% v 33$ (23)\%, p $<0.02$ and $p<0.003$, respectively), consistent with previous findings in migrated lymphocytes. ${ }^{37} 38$

\section{Adhesion molecules are expressed on migrated lymphocytes}

It has been shown that infiltrating lymphocytes in vivo ${ }^{12}$ and migrated lymphocytes in vitro highly express various adhesion molecules. ${ }^{39}$ In accordance with these findings, we found in both HC and SSc a high expression of CDIla (LFA-1; 86 (23)\% and 79 (32)\%, respectively), CD44 (H-CAM; 96 (10)\% and 97 (8\%), respectively), CD29 (VLA $\beta$ chain; 89 (8)\% and $93(6) \%$, respectively), and CD49d (integrin $\alpha_{4} ; 73(47) \%$ and 75 (14)\%, respectively) among migrated CD3+CD4+ cells. Differences between HC and SSc or within the different lymphocyte fractions were not significant. ${ }^{38}$

\section{Comparison of different patient subgroups}

We found no relevant differences in the TEM or the distribution of lymphocyte subsets between patients with diffuse or limited disease. We also found no significant differences when analysing patients with cutaneous disease $<5$ years or $>5$ years, nor when comparing patients undergoing photopheresis with those receiving other forms of treatment.

\section{DISCUSSION}

The data presented show an increased transendothelial migration of SSc T lymphocytes and a particular propensity of CD4+T cells towards migration. These observations contribute to the understanding of how the increased CD4/ CD8 ratio in perivascular infiltrates of patients with SSc may arise. Moreover, we investigated the lymphocytic expression of activation markers and adhesion molecules in these patients.

Indeed, the migration of PBMC through an human endothelial monolayer was increased in SSc in comparison with healthy people. Moreover, this increased percentage of migrated PBMC in SSc was mainly due to a surprisingly high proportion of CD4+ cells within the migrated CD3+ fraction. In contrast with SSc, we found an increased migratory capacity of CD8+ lymphocytes from $\mathrm{HC}$, corresponding to previous findings. ${ }^{33}{ }^{39}$ Thus, while the ratio of CD4/CD8 cells

\begin{tabular}{|c|c|c|c|c|c|c|c|c|}
\hline & \multicolumn{2}{|c|}{$\%$ CD4+HLA-DR+ } & \multicolumn{2}{|c|}{$\% \mathrm{CD} 4+\mathrm{CD} 25+$} & \multicolumn{2}{|c|}{ \% CD4+CD69+ } & \multicolumn{2}{|c|}{$\%$ CD4+CD45Ro+ } \\
\hline & $\overline{\mathrm{HC}}$ & SSc & $\overline{\mathrm{HC}}$ & SSc & $\overline{\mathrm{HC}}$ & SSc & $\overline{\mathrm{HC}}$ & SSc \\
\hline Ex vivo & $5(3)$ & $7(6)$ & $13(6)$ & $19(13)$ & $7(9)$ & $6(5)$ & $61(17)$ & $66(15)$ \\
\hline NAD & $4(2)$ & $6(5)$ & $13(3)$ & 21 (12) & $3(3)$ & $6(6)$ & 57 (12) & $59(16)$ \\
\hline BND & 10 (7) & $14(12)$ & $16(9)$ & $28(19)$ & $8(10)$ & $3(3)$ & $65(16)$ & 70 (15) \\
\hline MIG & $14(10)^{*}$ & $31(23)^{*}$ & 36 (37) & 31 (38) & $23(24)$ & $4(6)$ & $74(9)$ & 77 (10) \\
\hline
\end{tabular}


declined among migrated $\mathrm{T}$ cells of $\mathrm{HC}$, it even increased among migrated cells of patients with SSc. This finding is therefore apparently similar to the situation in scleroderma skin lesions, and, indeed, practically all our patients had signs of active skin involvement. In contrast, the processes responsible for the accumulation of CD8+ lymphocytes in SSC alveolitis are probably based on other mechanisms. ${ }^{1}$ These may include tumour necrosis factor $\alpha$ induced effects of primary human alveolar epithelial cells on lymphocyte migration $^{40}$ and differential effects of lung endothelial cells or, more likely, chemokines, which are all outside the scope of the present investigations.

Interestingly, many of the migrating CD4+ cells in SSc exhibited an activated, HLA-DR positive phenotype and highly expressed adhesion molecules. Although we cannot completely exclude the possibility that antigenic interactions between $\mathrm{T}$ cells and EC activate the $\mathrm{T}$ cell and lead to a concomitant increase in migratory capacity, we regard this as unlikely for several reasons: (a) $\mathrm{T}$ cells show signs of activation in peripheral blood; $(b)$ if local activation were occurring, the total number of $\mathrm{T}$ cells with activated phenotypes ought to increase. This, however, was not the case. Rather, while proportions of activated $\mathrm{T}$ cells increase among the migrating populations, they decrease among the NAD population (table 3 ); (c) in human T cells, HLA-DR is a late marker of activation and its expression becomes detectable 72 hours after activation with the potent activator phytohaemagglutinin ${ }^{41}{ }^{42}$ and exceeds pre-activation levels 6 days after activation with tetanus toxoid ${ }^{42} ;(d)$ we observed higher frequencies of HLA-DR+ lymphocytes mainly among migrated SSc lymphocytes and to a much lesser degree among HC lymphocytes.

Our data thus suggest that activated CD3+CD4+ lymphocytes as found in SSc peripheral blood are prone to migrate through vessel walls. This increased migratory capacity is likely to contribute to the perivascular accumulation of CD4+ lymphocytes, which is typical for the cutaneous manifestations in SSc. The data further suggest that $\mathrm{T}$ cells from patients with SSc are activated systemically, rather than locally, and migrate to the skin after such activation. Because the EC were derived from the umbilical cord, primary disease related EC changes could not account for the migratory behaviour of $\mathrm{T}$ cells.

In the context of these $\mathrm{T}$ cell abnormalities, it is of interest, that fibroblasts actively producing pro $\alpha \mathrm{l}$ (I) and pro $\alpha \mathrm{l}$ (III) collagen mRNAs are located next to the area of $\mathrm{T}$ cell infiltration, at least in localised SSc. ${ }^{43}$ Therefore, conceivably, these activated $\mathrm{T}$ cells may in turn have a causal relationship with fibrosis. ${ }^{44}$

In vivo, EC apoptosis mediated by antibodies has been seen in $\mathrm{SSc}^{7}$ and might facilitate the diapedesis of immune cells. To avoid endothelial damage and subsequent EC monolayer leakage in vitro, we kept the system serum-free and the migration time short. The confluence of the EC monolayer was carefully observed in each migration experiment. Moreover, perivascular lymphocytic infiltrates are found in SSc even in areas where endothelial damage is not evident, ${ }^{6}$ suggesting that lymphocytes also actively migrate through vessel walls.

Taken together, our observations suggest that, in addition to locally derived pro-migratory signals from fibroblasts ${ }^{45}$ and an increased permeability of damaged endothelium, an increased migratory capacity of CD4+ lymphocytes may promote the formation of cutaneous infiltrates in scleroderma. Our findings therefore provide a further step towards a more profound understanding of these intertwined processes in SSc. Targeting cell migration and thus preventing $\mathrm{T}$ cells from interfering with local cells may contribute to an interesting therapeutic approach.

\section{ACKNOWLEDGEMENTS}

We thank Mrs Daniela Eselsböck and Mrs Irene Radda for their help in the preparation and culture of EC, and Dr Günter Steiner for performing the line immunoassay.

\section{Authors' affiliations}

G H Stummvoll, M Aringer, J Grisar, C W Steiner, J S Smolen,

W B Graninger, Department of Rheumatology, Internal Medicine III, University of Vienna, Vienna, Austria

R Knobler, Department of Special Dermatology, Dermatology, University of Vienna, Vienna, Austria

\section{REFERENCES}

1 White B. Immunopathogenesis of systemic sclerosis. Rheum Dis Clin North Am 1996;22:695-708.

2 Furst DE. Rational therapy in the treatment of systemic sclerosis. Curr Opin Rheumatol 2000;12:540-4.

3 Furst DE, Clements PJ. Hypothesis for the pathogenesis of systemic sclerosis. J Rheumatol Suppl 1997:48:53-7.

4 Steen VD, Medsger T-AJ. Epidemiology and natural history of systemic sclerosis. Rheum Dis Clin North Am 1990;16:1-10.

5 White B. Immunologic aspects of scleroderma. Curr Opin Rheumatol 1995: 7:541-5.

6 Roumm AD, Whiteside TL, Medsger-TA J, Rodnan GP. Lymphocytes in the skin of patients with progressive systemic sclerosis. Quantification, subtyping, and clinical correlations. Arthritis Rheum 1984;27:645-53.

7 Sgonc R, Gruschwitz MS, Boeck G, Sepp N, Gruber J, Wick G. Endothelial cell apoptosis in systemic sclerosis is induced by antibody-dependent cellmediated cytotoxicity via CD95. Arthritis Rheum 2000;43:2550-62.

8 Kahari VM. Activation of dermal connective tissue in scleroderma. Ann Med 1993:25:51 1-18.

9 Domagala KJ, Hoser G, Kawalec M, Doboszynska A, Kawiak J, Droszcz W. Lymphocyte phenotyping in systemic sclerosis: a flow cytometry analysis of lymphocytes in bronchoalveolar lavage fluid. Anal Quant Cytol Histol 1997; 19:264-70.

10 Wells AU, Lorimer S, Majumdar S, Harrison NK, Corrin B, Black CM, et al. Fibrosing alveolitis in systemic sclerosis: increase in memory T-cells in lung interstitium. Eur Respir J 1995;8:266-71.

11 Prescott RJ, Freemont AJ, Jones CJ, Hoyland J, Fielding P. Sequential dermal microvascular and perivascular changes in the development of scleroderma. J Pathol 1992;166:255-63.

12 Gruschwitz M, von den Driesch P, Kellner I, Hornstein OP, Sterry W. Expression of adhesion proteins involved in cell-cell and cell-matrix interactions in the skin of patients with progressive systemic sclerosis. J Am Acad Dermatol 1992;27(Pt 1):169-77.

13 Claman HN, Giorno RC, Seibold JR. Endothelial and fibroblastic activation in scleroderma. The myth of the "uninvolved skin". Arthritis Rheum 1991;34:1495-501.

14 Sollberg S, Peltonen J, Uitto J, Jimenez SA. Elevated expression of beta 1 and beta 2 integrins, intercellular adhesion molecule 1, and endothelial leukocyte adhesion molecule 1 in the skin of patients with systemic sclerosis of recent onset. Arthritis Rheum 1992;35:290-8.

15 Majewski S, Hunzelmann N, Johnson JP, Jung C, Mauch C, ZieglerHeitbrock HW, et al. Expression of intercellular adhesion molecule-1 (ICAM-1) in the skin of patients with systemic scleroderma. J Invest Dermatol 1991;97:667-71.

16 Gustafsson R, Totterman TH, Klareskog L, Hallgren R. Increase in activated T cells and reduction in suppressor inducer T cells in systemic sclerosis. Ann Rheum Dis 1990:49:40-5.

17 Yurovsky VV. The repertoire of T-cell receptors in systemic sclerosis. Crit Rev Immunol 1995;15:155-65.

18 White B, Yurovsky VV. Oligoclonal expansion of V delta 1+ gamma/delta Tcells in systemic sclerosis patients. Ann N Y Acad Sci 1995:756:382-91.

19 Degiannis D, Seibold JR, Czarnecki M, Raskova J, Raska K. Soluble and cellular markers of immune activation in patients with systemic sclerosis. Clin Immunol Immunopathol 1990;56:259-70.

20 Gorla R, Airo P, Malagoli A, Carella G, Prati E, Brugnoni D, et al. CD4+ and CD8+ subsets: naive and memory cells in the peripheral blood of patients with systemic sclerosis. Clin Rheumatol 1994;13:83-7.

21 Stummvoll GH, Aringer M, Smolen JS, Koller M, Kiener HP, Steiner CW, et al. Derangement of apoptosis-related lymphocyte homeostasis in systemic sclerosis. Rheumatology (Oxford) 2000;39:1341-50.

22 Klein CL, Kohler H, Bittinger F, Wagner M, Hermanns I, Grant K, et al. Comparative studies on vascular endothelium in vitro. I. Cytokine effects on the expression of adhesion molecules by human umbilical vein, saphenous vein and femoral artery endothelial cells. Pathobiology 1994:62(4):199-208.

23 Raab M, Daxecker H, Markovic S, Karimi A, Griesmacher A, Mueller MM. Variation of adhesion molecule expression on human umbilical vein endothelial cells upon multiple cytokine application. Clin Chim Acta 2002;321:11-16.

24 Jaffe EA, Nachman RL, Becker CG, Minick CR. Culture of human endothelial cells derived from umbilical veins. Identification by morphologic and immunologic criteria. J Clin Invest 1973;52:2745-56.

25 Klein CL, Bittinger F, Kohler H, Wagner M, Otto M, Hermanns I, et al. Comparative studies on vascular endothelium in vitro. 3. Effects of cytokines on the expression of E-selectin, ICAM-1 and VCAM-1 by cultured human 
endothelial cells obtained from different passages. Pathobiology 1995;63:83-92.

26 Subcommittee for scleroderma criteria of the American Rheumatism Association Diagnostic and Therapeutic Criteria Committee. Preliminary criteria for the classification of systemic sclerosis (scleroderma). Arthritis Rheum 1980;23:581-90.

27 Kahaleh MB, Sultany GL, Smith EA, Huffstutter JE, Loadholt CB, LeRoy EC. A modified scleroderma skin scoring method. Clin Exp Rheumatol 1986:4:367-9.

28 Valentini G, Della-Rossa A, Bombardieri S, Bencivelli W, Silman AJ, D'Angelo $S$, et al. European multicentre study to define disease activity criteria for systemic sclerosis. II. Identification of disease activity variables and development of preliminary activity indexes. Ann Rheum Dis 2001;60:592-8.

29 Medsger-TA J, Steen VD. Classification, prognosis. In: Clements PJ, Furst DE, eds. Systemic sclerosis. Baltimore, Maryland: Williams\&Wilkins, 1996:51-64.

30 Lidington EA, Moyes DL, McCormack AM, Rose ML. A comparison of primary endothelial cells and endothelial cell lines for studies of immune interactions. Transpl Immunol 1999;7:239-46.

31 Galley HF, Blaylock MG, Dubbels AM, Webster NR. Variability in E-selectin expression, mRNA levels and sE-selectin release between endothelial cell lines and primary endothelial cells. Cell Biol Int 2000;24:91-9.

32 Oppenheimer-Marks N, Davis LS, Lipsky PE. Human T lymphocyte adhesion to endothelial cells and transendothelial migration. Alteration of receptor use relates to the activation status of both the T cell and the endothelial cell. J Immunol 1990;145:140-8.

33 Pietschmann P, Cush JJ, Lipsky PE, Oppenheimer-Marks N. Identification of subsets of human T cells capable of enhanced transendothelial migration. J Immunol 1992;149:1170-8.

34 Kahaleh MB, Fan PS. Mechanism of serum-mediated endothelial injury in scleroderma: identification of a granular enzyme in scleroderma skin and sera. Clin Immunol Immunopathol 1997;83:32-40.

34a Grisar J, Hahn P, Brosch S, Peterlik M, Smolen JS, Pietschmann P. Phenotypic characteristics of human monocytes undergoing transendothelial migration. Arthritis Res 2001;3:127-32.
35 Aringer $M$, Wintersberger $W$, Steiner $C W$, Kiener $H$, Presterl $E$, Jaeger $U$, et al. High levels of bcl-2 protein in circulating T lymphocytes, but not B lymphocytes, of patients with systemic lupus erythematosus. Arthritis Rheum 1994;37:1423-30.

36 Meheus L, van Venrooii WJ, Wiik A, Charles PJ, Tzioufas AG, Meyer O, et al. Multicenter validation of recombinant, natural and synthetic antigens used in a single multiparameter assay for the detection of specific anti-nuclear autoantibodies in connective tissue disorders. Clin Exp Rheumatol 1999;17:205-14.

37 Cush JJ, Pietschmann P, Oppenheimer-Marks N, Lipsky PE. The intrinsic migratory capacity of memory $T$ cells contributes to their accumulation in rheumatoid synovium. Arthritis Rheum 1992;35:1434-44.

38 Brezinschek RI, Oppenheimer-Marks N, Lipsky PE. Activated T cells acquire endothelial cell surface determinants during transendothelial migration. J Immunol 1999; 162:1677-84.

39 Galea P, Brezinschek R, Lipsky PE, Oppenheimer-Marks N. Phenotypic characterization of CD4-/alpha beta TCR+ and gamma delta TCR+ T cells with a transendothelial migratory capacity. J Immunol 1994;153:529-42.

40 Eghtesad M, Jackson HE, Cunningham AC. Primary human alveolar epithelia cells can elicit the transendothelial migration of CD14+ monocytes and CD3+ lymphocytes. Immunology 2001;102:157-64.

41 Cotner T, Williams JM, Christenson L, Shapiro HM, Strom TB, Strominger J. Simultaneous flow cytometric analysis of human $\mathrm{T}$ cell activation antigen expression and DNA content. J Exp Med 1983;157:461-72.

42 Ko HS, Fu SM, Winchester RJ, Yu DT, Kunkel HG. la determinants on stimulated human $T$ lymphocytes. Occurrence on mitogen- and antigenactivated T cells. J Exp Med 1979;150:246-55

43 Kahari VM, Sandberg M, Kalimo H, Vuorio T, Vuorio E. Identification of fibroblasts responsible for increased collagen production in localized scleroderma by in situ hybridization. J Invest Dermatol 1988;90:664-70.

44 White B. Pathogenesis: immune aspects. In: Clements PJ, Furst DE, eds. Systemic sclerosis. Baltimore, Maryland: Williams\&Wilkins, 1996:229-50.

45 Denton CP, Shi WX, Sutton A, Abraham DJ, Black CM, Pearson JD. Scleroderma fibroblasts promote migration of mononuclear leucocytes across endothelial cell monolayers. Clin Exp Immunol 1998;1 14:293-300. 